\title{
Pemodelan dan Simulasi Dinamika Lengan Robot 3-DOF Menggunakan Perangkat Lunak Open Source
}

\author{
Indar Sugiarto \\ Jurusan Teknik Elektro, Fakultas Teknologi Industri, Universitas Kisten Petra \\ Jl. Siwalankerto 121-131, Surabaya - 60236 \\ Email: indi@petra.ac.id
}

\begin{abstract}
ABSTRAK
Dalam paper ini dijelaskan salah satu metode alternatif untuk analisa dinamik sebuah robot lengan dengan menggunakan perangkat lunak open source yang disebut ODE (open dynamic engine). Dengan menggunakan ODE, sebuah robot lengan dapat dimodelkan dan disimulasikan dengan sederhana dan memberikan hasil yang akurat. Robot lengan yang dimodelkan dan disimulasikan dalam paper ini adalah Movemaster EX RV-M1 dari Mitsubishi. Simulasi dilakukan setelah model robot selesai dibuat dan simulasi dijalankan dengan membuat supaya semua link robot bergerak serempak membentuk garis lurus dan berputar dari sudut $0^{\circ}$ hingga $100^{\circ}$. Dari hasil pemodelan dan simulasi didapatkan bahwa masing-masing revolute joint dari robot tersebut membutuhkan torsi yang berbeda-beda dan ditemukan pada kecepatan $1.26 \mathrm{rad} / \mathrm{s}$, joint siku (elbow) membutuhkan torsi yang lebih besar untuk menggerakkan lengan depan (forearm) dari robot, yaitu sebesar 3101.79 g.m $\mathrm{m}^{2} . \mathrm{s}^{-2}$. Torsi yang besar ini tidak hanya diakibatkan karena beban link yang harus diangkat, tetapi juga constraint force yang harus dilawan oleh joint siku (elbow) saat bergerak bersama-sama dengan joint yang lain. Hasil penelitian ini tidak menghasilkan program visualisasi tetapi dapat dikembangkan misalnya untuk melengkapi program-program simulator yang kebanyakan dikembangkan hanya berdasarkan simulasi dan pemodelan kinematika saja.
\end{abstract}

Kata kunci: pemodelan, simulasi, robot lengan 3DOF, ODE

\section{ABSTRACT}

This paper describes an alternative method for analyzing robot dynamics using open source software so-called ODE (open dynamic engine). Using ODE, an arm robot can be modeled and simulated in a simple but accurate fashion. The arm robot which is being modeled and simulated in this paper is the Movemaster EX RV-M1 from Mitsubishi. The simulation is performed after the robot has been completely modeled and the simulation was made so that all links within the robot will move simultaneously forming a straight line and rotating from $0^{\circ}$ to $100^{\circ}$. The modeling and simulation result shows that each revolute joint of the robot requires distinct torque and it is found that at the speed of $1.26 \mathrm{rad} / \mathrm{s}$, the elbow joint has the higher torque to move the body at the level of $3101.79 \mathrm{~g} . \mathrm{m}^{2} . \mathrm{s}^{-2}$. This high torque was due to constraint force when the joint was moving altogether. This research does not produce any visualization effect but it can be extended to enrich any other simulator program which works according to kinematics modeling only.

Keywords: modeling, simulation, robot arm 3DOF, $O D E$

\section{PENDAHULUAN}

Dalam penelitian sebelumnya tentang simulasi dan pemodelan sistem-sistem fisika dan mekanika, diketahui bahwa salah satu perangkat lunak open source yang kenal dengan nama ODE (open dynamic engine) merupakan salah satu framework yang kompleks dan dilengkapi dengan pustaka-pustaka yang berisi fungsi-fungsi untuk melakukan kalkulasi numerik guna pemodelan sistem dinamis [1].

ODE tersusun atas algoritma-algoritma untuk mensimulasikan interaksi dinamika antar benda-

Catatan: Diskusi untuk makalah ini diterima sebelum tanggal 1 Desember 2008. Diskusi yang layak muat akan diterbitkan pada Jurnal Teknik Elektro volume 9, nomor 1, Maret 2009. benda dalam sebuah kerangka ruang berdasarkan konsep dinamika benda tegar (rigid body). Namun ODE bukanlah program yang dapat menampilkan gambar / grafis, tetapi hanyalah pustaka yang berisi rutin-rutin untuk perhitungan gerakan sebuah benda berikut interaksinya dengan benda-benda lain dalam kerangka ruang yang sama berdasarkan hukum fisika, utamanya mekanika klasik (Newtonian mechanics) [2]. ODE sendiri tersusun atas dua komponen utama, yaitu komponen simulasi dinamika benda tegar (rigid body dynamics simulation engine) dan komponen pendeteksi tumbukan (collision detection engine). Hasil-hasil perhitungan oleh ODE selanjutnya dapat digunakan oleh program-program simulator grafis untuk menghasilkan efek visual ataupun digunakan langsung oleh sistem kontrol robot yang berbasis PC. 
Salah satu kekuatan ODE yang menonjol adalah solusi terhadap permasalahan Linear Complementary Problem (LCP) menggunakan teknik Lagrange Multiplier yang banyak muncul pada sistem dinamis yang melibatkan fenomena gesekan dan tumbukan [3], [6]. Di dalam ODE dikenal beberapa obyek dasar yang parameter-parameternya melambangkan besaran fisik dari sebuah sistem dinamik dan sering digunakan dalam analisa kinematika maupun dinamika dari sebuah robot. Obyek-obyek dasar tersebut adalah: world, body, geom, space, dan joint. Sintaks yang digunakan oleh ODE sama dengan bahasa pemrograman $\mathrm{C}++$ dan bisa berinteraksi dengan program-program yang dibuat dengan ANSIC.

Pada penelitian ini, ODE versi 0.5 digunakan untuk mendapatkan model dinamika dari robot lengan 3DOF yang presisi sekaligus melakukan simulasi terhadap model yang dibuat. Robot yang dimodelkan adalah Movemaster EX RV-M1 yang merupakan robot industri bertipe articulated configuration robot (RRR) [4]. Penelitian ini tidak menghasilkan program visualisasi tetapi dapat dikembangkan misalnya untuk melengkapi program-program yang dibuat untuk project-project semacam [5] yang dikembangkan hanya berdasarkan simulasi dan pemodelan kinematika saja. Untuk memudahkan pemodelan dan simulasi dalam paper ini, robot Movemaster EX RVM1 dianggap memiliki link-link yang terhubung dengan joint constraint yang bersifat holonomic.

\section{PEMODELAN UNTUK SIMULASI}

Konstruksi robot lengan Movemaster EX RV-M1 dan representasi simbolisnya ditunjukkan pada gambar 1. Dari buku manual robot Movemaster EX RV-M1 [4], diperoleh data-data seperti pada table 1.

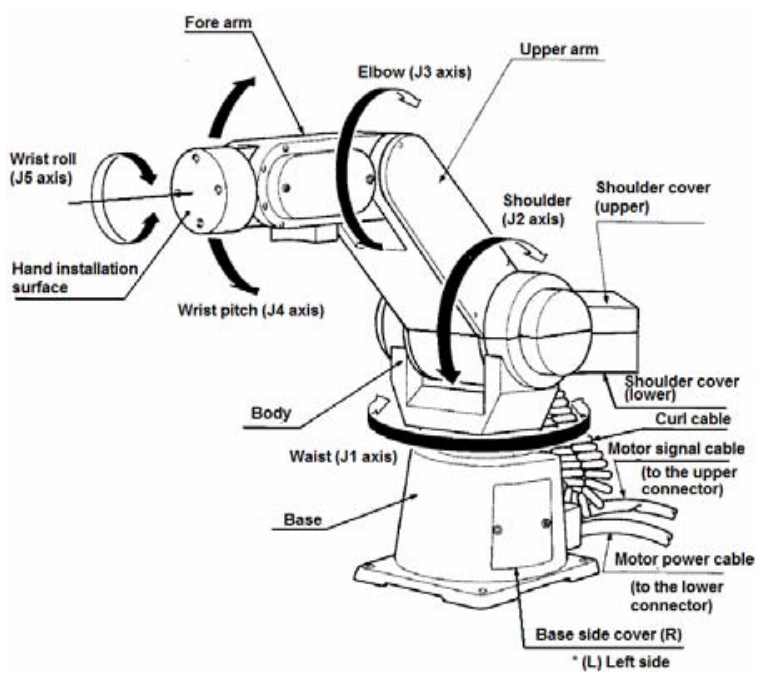

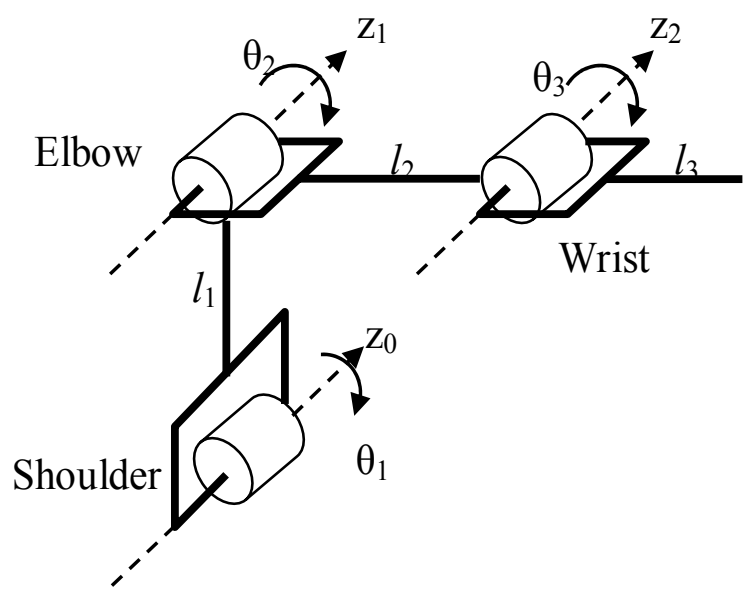

Gambar 1. Konstruksi robot lengan Movemaster EX RV-M1 dan representasi simbolisnya

Tabel 1. Spesifikasi robot Movemaster EX RV-M1

\begin{tabular}{ll}
\hline Dimensi lengan atas (upper arm) & $250 \times 106 \times 94 \mathrm{~mm}$ \\
Panjang lengan depan (fore arm) & $160 \times 70 \times 91 \mathrm{~mm}$ \\
Panjang pergelangan (wrist) & $72 \times 30 \times 30 \mathrm{~mm}$ \\
Kecepatan max bahu (shoulder) & $72^{\circ} / \mathrm{s}$ \\
Kecepatan max siku (elbow) & $109^{\circ} / \mathrm{s}$ \\
Kecepatan max pergelangan (wrist) & $100^{\circ} / \mathrm{s}$ \\
Massa lengan atas & $0.255 \mathrm{~kg}$ \\
Massa lengan depan & $0.306 \mathrm{~kg}$ \\
Massa pergelangan & $0.102 \mathrm{~kg}$ \\
\hline
\end{tabular}

Seperti diketahui, dalam analisa dinamik sebuah robot biasanya digunakan salah satu dari formulasi NewtonEuler ataupun Lagrangian. Dalam paper ini, analisa dinamik dari robot lengan didasarkan pada formulasi Lagrangian karena formulasi ini secara native sudah terimplementasi di dalam ODE. Persamaan dasar dari fungsi Lagrangian L didapatkan dari selisih antara energi kinetik total $K$ dan energi potensial $P$ yang tersimpan dalam sebuah sistem dinamik, yang dalam koordinat Kartesius dapat dinyatakan sebagai:

$L=K(\boldsymbol{x})-P(\boldsymbol{x})$

dengan $\boldsymbol{x}=\left[x_{1}, x_{2}, \ldots, x_{n}\right]^{\mathrm{T}}$

Atau jika menggunakan konsep generalized coordinates $\boldsymbol{q}=\left[q_{1}, q_{2}, \ldots, q_{s}\right]^{\mathrm{T}}$, dimana $x_{i}(\mathrm{i}=1,2, \ldots \mathrm{n})$

adalah fungsi dari $\boldsymbol{q}$ dan $\boldsymbol{x}_{i}$ adalah fungsi dari $\boldsymbol{q}$ dan $\bar{q}$, maka fungsi Lagrangian pada persamaan 1 di atas dapat ditulis menjadi:

$L=K(q, \dot{q})-P(q)$

Untuk robot lengan dengan n-link, maka energi kinetik yang dimiliki untuk link ke-i adalah: 
$K_{i}=\frac{1}{2} m_{i} \bar{v}_{i}^{T} \bar{v}_{i}+\frac{1}{2} \bar{\omega}_{i}^{T} \mathbf{I}_{i} \bar{\omega}_{i}$

Dengan demikian,

$$
K=\sum_{i=1}^{n} K_{i}
$$

Dengan memanfaatkan persamaan kinematik untuk lengan robot dengan n-link, didapatkan:

$\bar{x}=J \dot{q}$

dimana $\dot{\boldsymbol{X}}=\left[\begin{array}{ll}\boldsymbol{v}^{T} & \boldsymbol{\omega}^{T}\end{array}\right]$, dengan $\boldsymbol{v}$ adalah vektor kecepatan linier dan $\boldsymbol{\omega}$ adalah vektor kecepatan sudut serta $J$ adalah matrix Jacobian dengan susunan sebagai berikut:

$I=\left[\begin{array}{llll}J_{11}, & J_{12}, & \cdots, & J_{M n} \\ J_{a 1}, & J_{a 2}, & \cdots, & J_{a n}\end{array}\right] \in R^{6 x n}$

Dengan demikian, vektor kecepatan linier $\boldsymbol{v}$ dan vektor kecepatan sudut $\omega$ dapat ditulis sebagai:

$v=J_{11} \dot{q}_{1}+J_{12} \dot{q}_{2}+\cdots,+J_{l n} \dot{q}_{n}$

$\omega=J_{a 1} \tilde{q}_{1}+J_{a 2} \dot{q}_{2}+\ldots,+J_{a n} \dot{q}_{n}$

dimana $J_{l i}$ dan $J_{a i}$ pada persamaan 6 adalah vektorvektor yang berhubungan dengan kecepatan linier dan kecepatan sudut dari masing-masing persendian.

Dan jika diterapkan pada persamaan 3 akan menghasilkan:

$K=\frac{1}{2} \dot{q}^{T} D(q) \dot{q}$

dimana $D(\boldsymbol{q})$ adalah matrix inertia atau tensor inertia dari sebuah robot lengan dengan n-link.

Rumusan untuk energi potensial dari robot lengan dengan n-link adalah:

$P=\sum_{i=1}^{n} m_{i} g^{T} \bar{p}_{0 i}$

dimana $\boldsymbol{g}$ adalah vektor gravitasi, $\overline{\boldsymbol{p}}_{0 \mathrm{i}}$ adalah vektor posisi yang diukur dari basis robot ke pusat massa $m_{i}$.

Fungsi Lagrangian L kemudian dapat ditulis kembali menjadi:

$$
\begin{aligned}
L & =K-P \\
& =\frac{1}{2} \dot{\boldsymbol{q}}^{T} \boldsymbol{D}(\boldsymbol{q}) \dot{\boldsymbol{q}}-\sum_{i=1}^{n} m_{i} \boldsymbol{g}^{T} \overline{\boldsymbol{p}}_{0 i}
\end{aligned}
$$

$$
=\frac{1}{2} \sum_{i=1}^{n} \sum_{j=1}^{n} d_{i j}(\boldsymbol{q}) \dot{\boldsymbol{q}}_{i} \overline{\boldsymbol{q}}_{j}-\sum_{i=1}^{n} m_{i} \boldsymbol{g}^{T} \overline{\boldsymbol{p}}_{0 i}
$$

Turunan parsial dari fungsi Lagrangian L terhadap $\overline{\boldsymbol{q}}_{\bar{i}}$ adalah:

$\frac{\partial L}{\partial \dot{q}_{i}}=\frac{\partial}{\partial \dot{q}_{i}}\left(\frac{1}{2} \sum_{i=1}^{n} \sum_{j=1}^{n} d_{i j}(\boldsymbol{q}) \dot{q}_{i} \dot{q}_{j}\right)=\sum_{j=1}^{n} d_{i j}(\boldsymbol{q}) \dot{q}_{j}$

Dengan demikian,

$\frac{d}{d t} \frac{\partial L}{\partial \dot{q}_{i}}=\sum_{j=1}^{n} d_{i j}(\boldsymbol{q}) \ddot{q}_{j}+\sum_{j=1}^{n} \sum_{k=1}^{n} \frac{\partial\left(d_{i j}(\boldsymbol{q})\right)}{\partial q_{k}} \dot{q}_{k} \bar{q}_{j}$

Sedangkan

$\frac{\partial L}{\partial q_{i}}=\frac{1}{2} \sum_{k=1}^{n} \sum_{j=1}^{n} \frac{\partial d_{k j}(\boldsymbol{q})}{\partial q_{i}} \bar{q}_{k} \dot{q}_{j}-\sum_{j=1}^{n} m_{j} \boldsymbol{g}^{T}\left(\frac{\partial \bar{p}_{0 j}}{\partial q_{i}}\right)$

Seperti diketahui bahwa,

$\frac{d}{d t}\left(\frac{\partial L}{\partial \dot{q_{i}}}\right)-\frac{\partial L}{\partial q_{i}}=\tau_{i}$

Maka jika tiga persamaan terakhir ini digabungkan, akan didapatkan persamaan diferensial untuk robot lengan dengan n-link sebagai berikut:

$\sum_{i=1}^{n} d_{i j}(\boldsymbol{q}) \ddot{q}_{j}+\sum_{j=1}^{n} \sum_{k=1}^{n} \frac{\partial\left(d_{i j}(\boldsymbol{q})\right)}{\partial q_{k}} \dot{q}_{k} \dot{q}_{j}=$

$\frac{1}{2} \sum_{k=1}^{n} \sum_{j=1}^{n} \frac{\partial d_{k j}(\boldsymbol{q})}{\partial q_{i}} \dot{q}_{k} \dot{q}_{j}+\sum_{j=1}^{n} m_{j} \boldsymbol{g}^{T}\left(\frac{\partial \bar{p}_{0 j}}{\partial q_{i}}\right)=\tau_{i}$

$\sum_{i=1}^{\text {atau }} d_{i j}(\boldsymbol{q}) \ddot{q}_{j}+\sum_{j=1}^{n} \sum_{k=1}^{n} d_{i j k} \dot{q}_{k} \dot{q}_{j}+\phi_{i}=\tau_{i}$

yang secara sederhana dapat ditulis sebagai:

$D(\dot{q}) \ddot{q}+H(\dot{q}, \dot{q}) \dot{q}+G(\dot{q})=\tau$

dimana $D(\boldsymbol{q})$ adalah matrix inertia, $H(\boldsymbol{q}, \tilde{\boldsymbol{q}}) \dot{q}$ adalah vektor kopling kecepatan, dan $\boldsymbol{G}(\boldsymbol{q})$ adalah vektor beban gravitasi.

Dengan menyelesaikan persamaan ini, akan dihasilkan nilai torsi yang diperlukan untuk memutar link ke-i dari lengan robot dengan kecepatan seperti ditentukan pada bagian $H(\boldsymbol{q}, \overline{\boldsymbol{q}}) \overline{\boldsymbol{q}}$. Informasi torsi ini diperlukan saat proses disain sistem kontrol untuk lengan robot tersebut. 
Untuk memodelkan dan mensimulasikan robot lengan dengan menggunakan ODE, diagram alir yang digunakan dalam paper ini seperti pada gambar 2 .

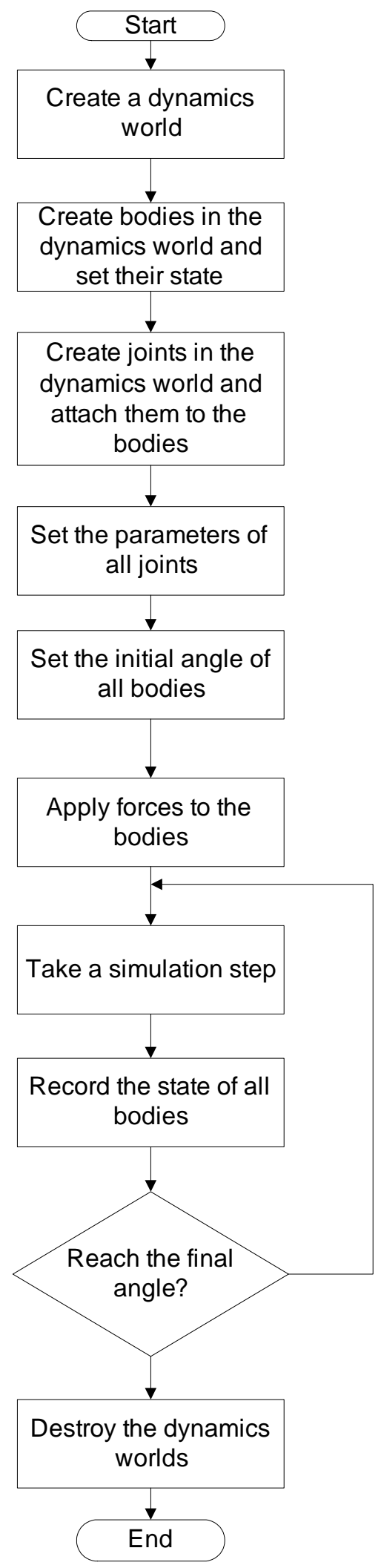

Gambar 2. Diagram alir pemodelan dan simulasi robot lengan dengan ODE
Dalam ODE, body pada dasarnya adalah sebuah obyek program untuk menyatakan sebuah benda tegar padat (solid rigid body). Body secara default tidak memiliki bentuk bangun tertentu. Tetapi untuk mempermudah pengguna, ODE menyediakan beberapa bentuk bangun dasar seperti kubus, prisma, silinder, bola, dan kapsul. Parameter-parameter sebuah body adalah sebagai berikut:

- Vektor posisi dari titik referensinya (biasanya pusat massanya), dinyatakan dalam sebuah vektor $\boldsymbol{p}^{\mathrm{T}}=\left[\begin{array}{lll}p_{x} & p_{y} & p_{z}\end{array}\right]$

- Kecepatan linier dari titik referensinya, dinyatakan dalam vektor $\boldsymbol{v}^{\mathrm{T}}=\left[\begin{array}{lll}v_{x} & v_{y} & v_{z}\end{array}\right]=\left[\mathrm{d} p_{x} / \mathrm{dt} \mathrm{d} p_{y} / \mathrm{dt} \mathrm{d} p_{z} / \mathrm{dt}\right]$

- Orientasi dari body, yang bisa dinyatakan dalam matrix rotasi $R(3 \times 3)$ atau vektor quaternion $\boldsymbol{q}^{\mathrm{T}}=$ $\left[\begin{array}{llll}q_{s} & q_{x} & q_{y} & q_{z}\end{array}\right]$

- Kecepatan sudut $\boldsymbol{\omega}^{\mathrm{T}}=\left[\begin{array}{lll}\omega_{x} & \omega_{y} & \omega_{z}\end{array}\right]$, yang menunjukkan perubahan orientasi body sepanjang waktu

- Massa

- Tensor inersia, berupa matrix 3x3 yang berisi informasi bagaimana massa dari sebuah body terdistribusi seputar pusat massa dari body tersebut.

World adalah sebuah kelas yang terdiri dari (dan mengikat) obyek-obyek body (secara dinamis maupun statis) bersama dengan variabel gaya dan waktu.

Pada dasarnya, simulasi dinamika menggunakan ODE bekerja dengan cara mengubah (memajukan) variabel waktu dari world dengan step tertentu dan kemudian meng-update state dari masing-masing body di dalam world yang bersangkutan berdasarkan hukum mekanika dan melibatkan gaya yang ada/didefinisikan dalam world tersebut. Berikut adalah cuplikan program untuk membuat link pertama beserta joint-nya dari robot lengan Movemaster EX dengan menggunakan obyek body berbentuk kubus. Dalam memodelkan lengan robot Movemaster EX, dipilih joint bertipe hinge karena pergerakan dari link-nya bersifat revolute.

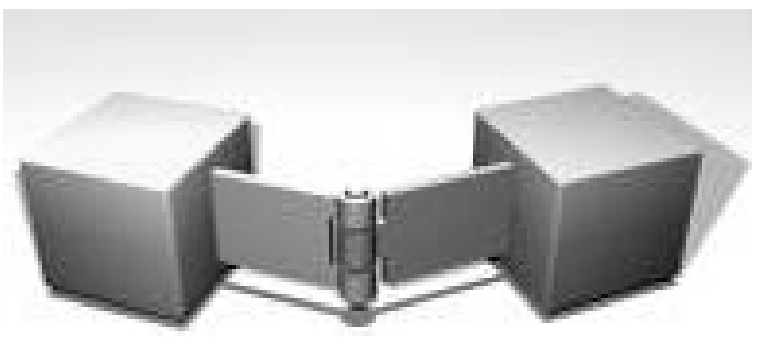

Gambar 3. Struktur joint hinge yang digunakan untuk memodelkan persendian bertipe revolute 
dWorldID_world = dWorldCreate();

dWorldSetGravity (world, $0,0,-9.81$ );

// Create a body

dBodyID UpperArm = dBodyCreate $($ world);

$\mathrm{dBodyID}$ ForeArm = dBodyCreate $($ world);

dMass mass:

dMassSetBoxTotal(\&mass,0.255f,0.25f,0.106f,0.094f);

dMatrix3 Theta1 = 0;

dQuaternion Q1;

dBodySetMass(UpperArm,\&mass);

dBodySetPosition(UpperArm, 0,0,0);

dBodySetRotation (UpperArm, Theta1);

dBodySetQuaternion (UpperArm, Q1);

dBodySetAngularVel (UpperArm, 1.26f, 0, 0);

// equivalent with $72 \%$

// Create joint

dJointGroupID ShoulderGroup = dJointGroupCreate (0);

JointID Shoulder $=$ dJointCreateHinge $($ world,

ShoulderGroup);

dJointAttach (Shoulder, UpperArm, ForeArm);

dJointSetHingeAnchor (Shoulder, 250.0f, 53.0f, 47.0f);

dJointSetHingeAxis (Shoulder, 250.0f, 106.0f, 47.0f);

Geom adalah parameter yang digunakan untuk merepresentasikan bentuk geometri dari sebuah obyek body untuk dipakai dalam algoritma pendeteksi tumbukan. Jadi setelah sebuah obyek body dibuat, obyek tersebut harus diberi parameter geom supaya bisa disimulasikan jika bertumbukan dengan obyek body lainnya. Space adalah sebuah obyek yang mengikat satu atau lebih geom menjadi satu kesatuan dan mengatur / mengendalikan algoritma pendeteksi tumbukan. Dengan kata lain, geom dan space adalah abstraksi dari body dan world. Berikut ini adalah kelanjutan dari skrip sebelumnya.

$\mathrm{dSpaceID}$ space $=\mathrm{dHashSpaceCreate}(0) ;$

// Create a geom.

dGeomID geom = dCreateBox (space,1,1,1);

// Bind together our previously created body/link and the geom

dGeomSetBody(geom,UpperArm);

Pada skrip di atas, obyek body diikat dengan sebuah geom. Jika sebuah geom tidak memiliki representasi body, maka geom tersebut bersifat statis. Cara seperti ini digunakan untuk menciptakan sebuah "base" untuk meletakkan model robot lengan yang dibuat. Sebuah obyek body bisa diikat dengan obyek body yang lain sehingga menjadi sebuah persendian, rantai, ataupun interaksi lainnya.

Beberapa joint bisa diikat dalam satu kesatuan yang disebut joint group. Tipe data dJointGroup digunakan untuk mengasosiasikan sebuah kelas dengan beberapa obyek joint. Kegunaan joint group adalah untuk memastikan bahwa hukum-hukum mekanika telah diaplikasikan pada masing-masing joint di dalam group tersebut dan mengurangi terjadi joint error. Namun dalam paper ini, joint group yang dibuat akan bernilai 1 karena hanya terdiri dari 1 buah joint saja (yaitu bertipe hinge).

\section{HASIL SIMULASI}

Setelah parameter-parameter dari body dan joint dimasukkan, langkah berikutnya adalah melakukan simulasi sekuensial menggunakan fungsi simulasi yang disediakan ODE. Dalam paper ini dipilih fungsi dWorldStep() karena meskipun membutuhkan sumber daya memori komputer paling besar dan lebih lambat tetapi hasil simulasinya sangat akurat (dibandingkan fungsi dWorldQuickStep()). Dalam simulasi ini, lengan robot dibuat lurus dan dimulai dari sudut $0^{\circ}$. Motor pada ketiga link dari lengan robot tersebut harus membuat supaya lengan robot tetap dalam kondisi lurus dan torsi yang dibutuhkan oleh motor-motor tersebut akan disimpan di memori dalam bentuk array. Berikut adalah contoh skrip program yang dibuat (ditunjukkan hanya pada bagian link pertama saja, link-link yang lain memiliki format yang mirip).

//let's simulate

static float nbSecondsByStep $=0.001 \mathrm{f}$

// Find the time elapsed between last time

float nbSecsElapsed = time.elapsed()/1000.0f;

// Find the corresponding number of steps that must be taken

Int nbStepsToPerform = 0;

// Make these steps to advance world time

do

\{

// Step world

dWorldStep(world, nbSecondsByStep);

// Remove all temporary collision joints after the stepping dJointGroupEmpty(ShoulderGroup);

// Record body's state

AngleDataUpperArm[nbStepsToPerform] =

dBodyGetRotation(UpperArm);

TorqueDataUpperArm[nbStepsToPerform] = dBodyGetTorque(UpperArm);

nbStepsToPerform++;

II... and the other links as well!

\} while dBodyGetRotation(UpperArm) $>=(100 * 2 * \mathrm{pi} / 180)$;

// Restart the elapsed time counter

time.restart);

Hasil dari simulasi di atas adalah 3 set array yang terdiri dari 2 buah data bertipe real, yaitu AngleDataUpperArm*, TorqueDataUpperArm*, AngleDataForeArm*, TorqueDataUpperArm*, AngleDataWrist*, TorqueDataWrist*. Keenam array tersebut kemudian disimpan ke dalam sebuah file bertipe ASCII untuk diolah lebih lanjut menggunakan Excel. Pada percobaan ini, kecepatan dari masing- 
masing link mengikuti update dari kecepatan maksimum dari link pertama seperti ditunjukkan pada tabel 1 .

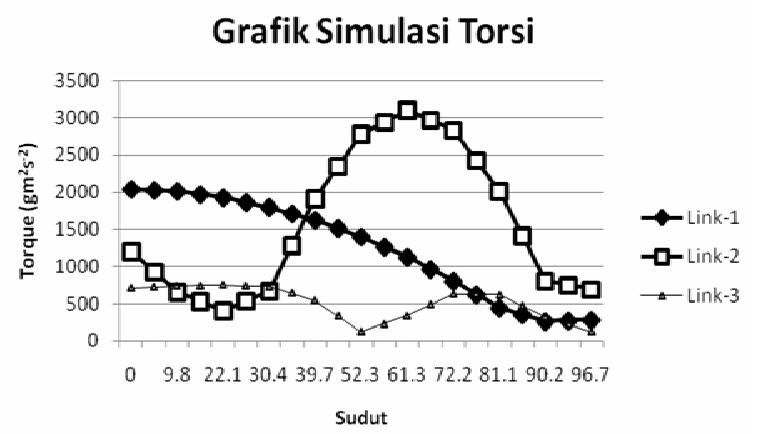

Gambar 4. Hasil simulasi ODE yang menghasilkan perhitungan Torsi selama lengan robot bergerak dari $0^{\circ}$ hingga $100^{\circ}$

Tujuannya adalah untuk mengetahui torsi maksimum yang diperlukan motor untuk menggerakkan masingmasing link dari robot tersebut. Berikut ini adalah hasil simulasi dari ODE dengan menggunakan datadata Robot Movemaster EX RV-M1.

Dari hasil simulasi oleh ODE seperti ditunjukkan pada gambar 4, terlihat bahwa masing-masing joint akan menghasilkan torsi yang berbeda untuk menjaga supaya lengan robot tetap berada pada kondisi lurus. Terlihat bahwa link-1 (lengan atas dari robot) membutuhkan torsi awal yang besar namun kemudian menurun landai seiring dengan pergerakan dari joint-joint yang lain. Sedangkan link-2 terlihat justru mengalami kenaikan torsi pada saat lengan robot berada pada posisi tengah. Ini menunjukkan bahwa joint yang terhubung dengan lengan depan (forearm) membutuhkan tenaga yang lebih untuk melawan gravitasi. Seperti disebutkan dalam [4], lengan depan memiliki sudut putaran awal sebesar $110^{\circ}$ dan juga terhubung dengan link-3 (pergelangan) yang dapat bergerak bebas $\pm 90^{\circ}$. Kondisi ini memaksa link-2 bekerja lebih berat dari sebelumnya. Sedangkan link-3 (pergelangan) memiliki distribusi torsi yang hampir merata dan lebih kecil dari link-link yang lain (sesuai dengan dimensi dan distribusi massa-nya). Berikut ini intisari dari torsi maksimum yang dibutuhkan oleh masing-masing joint untuk menggerakkan link dengan kecepatan $72^{\circ}$ /s atau 1.26 $\mathrm{rad} / \mathrm{s}$.

Informasi tentang torsi maksimum seperti di atas sangat penting dalam disain robot sesungguhnya, khususnya dalam pemilihan tipe dan kapasitas motor yang digunakan serta perbandingan/ratio dari gigi jika menggunakan gearbox.
Tabel 2. Torsi maksimum masing-masing joint pada kecepatan $1.26 \mathrm{rad} / \mathrm{s}$

\begin{tabular}{ll}
\hline Joint & Torsi max $\left(\mathbf{g} \cdot \mathbf{m}^{2} \cdot \mathbf{s}^{-2}\right)$ \\
\hline Bahu (shoulder) & 2038.811 \\
Siku (elbow) & 3101.79 \\
Pergelangan (wrist) & 752.539 \\
\hline
\end{tabular}

\section{KESIMPULAN}

Sebuah metode alternatif untuk analisa dinamik sebuah robot lengan dengan menggunakan perangkat lunak open source telah dipaparkan. Dalam paper ini, perangkat lunak yang digunakan adalah ODE (open dynamic engine) yang banyak digunakan dalam aplikasi-aplikasi simulasi dan pemodelan sistem dinamika yang membutuhkan derajat akurasi dan presisi yang tinggi sementara proses kalkulasinya dilakukan hampir real time. Dengan menggunakan ODE, sebuah robot lengan dapat dimodelkan dan disimulasikan dengan sederhana dan menghasilkan hasil yang akurat. Robot lengan yang dimodelkan dan disimulasikan dalam paper ini adalah Movemaster EX RV-M1 dari Mitsubishi. Simulasi dilakukan setelah model robot selesai dibuat dan simulasi dijalankan dengan membuat supaya semua link robot bergerak serempak membentuk garis lurus dan berputar dari sudut $0^{\circ}$ hingga $100^{\circ}$. Dari hasil pemodelan dan simulasi didapatkan bahwa masingmasing revolute joint dari robot tersebut membutuhkan torsi yang berbeda-beda dan ditemukan bahwa pada kecepatan $1.26 \mathrm{rad} / \mathrm{s}$, joint siku (elbow) membutuhkan torsi yang lebih besar untuk menggerakkan lengan depan (forearm) dari robot, yaitu sebesar 3101.79 g.m ${ }^{2} . \mathrm{s}^{-2}$. Torsi yang besar ini tidak hanya diakibatkan karena beban link yang harus diangkat, tetapi juga constraint force yang harus dilawan oleh joint siku saat bergerak bersamasama dengan joint yang lain. Untuk penelitian ke depan, akan lebih baik jika hasil simulasi juga bisa ditampilkan dengan menggunakan perangkat lunak open source lain seperti OGRE (Object-Oriented Graphics Rendering Engine) ataupun Irrlich.

\section{DAFTAR PUSTAKA}

[1] Indar Sugiarto, "Simulasi dan Pemodelan FisikaMekanika Menggunakan Perangkat Lunak Open Source", Prosiding Seminar Nasional Basic Science 6. Universitas Brawijaya, Malang. 2009.

[2] ODE website (http://www.ode.org)

[3] David Baraff, "Analytical Methods for Dynamic Simulation of Non-penetrating Rigid Bodies", Computer Graphics. 1989. Vol. 23, no. 3:223232. 
[4] Mitsubishi, "Industrial Micro-Robot System Model RV-M1", Instruction Manual. 1992.

[5] J. Świder, K. Foit, G. Wszołek, D. Mastrowski, "The Off-line Programming and Simulation Software for the Mitsubishi Movemaster RVM1 Robot", Journal of Achievement in
Materials and Manufacturing Engineering. Vol 20 (2):499-502. 2007.

[6] Man Zhihong, Robotics for Computer Engineering Students, Singapore: Prentice HallPearson Education South Asia Pte Ltd. 2004. 